\title{
Aceitabilidade de flocos desidratados de abóbora
}

\section{Dehydrated pumpkin flakes acceptability}

Carmem Lygia Burgos AMBRÓSIO'

Florisbela de Arruda Camara e Siqueira CAMPOS²

Zelyta Pinheiro de FARO²

R E S U M O

\section{Objetivo}

Avaliar a aceitabilidade de flocos desidratados de abóbora, uma vez que tal produto pode constituir uma alternativa no combate à hipovitaminose A.

\section{Métodos}

Os flocos foram avaliados quanto às características microbiológicas, por meio das análises de coliformes a $45^{\circ} \mathrm{C}$, Escherichia coli, Staphylococcus aureus, Salmonela sp, contagem de bolores e leveduras, e características físico-químicas, por meio da análise de umidade, proteínas, lipídios, cinzas, fibra alimentar, carboidratos, carotenóides, estabilidade ao longo do tempo de armazenamento e aceitabilidade dos flocos adicionados ao feijão e ao pirão de 188 adultos e 67 crianças, respectivamente.

\section{Resultados}

Os flocos estavam adequados quanto às características microbiológicas e físico-químicas e os percentuais de aceitação de $95,21 \%$ para os adultos e $95,52 \%$ para as crianças.

\section{Conclusão}

Os flocos desidratados de abóbora podem ser utilizados em larga escala para o estudo do efeito deste produto no combate à hipovitaminose $A$.

Termos de indexação: análise sensorial; carotenóides; flocos desidratados de abóbora; hipovitaminose A.

\section{A B S T R A C T}

\section{Objective}

The objective of this study was to evaluate the acceptability of flakes since this product can be an alternative in the fight against hypovitaminosis $A$.

\footnotetext{
1 Doutoranda, Curso de Pós-Graduação em Nutrição, Universidade Federal de Pernambuco. Cidade Universitária, 50670901, Recife, PE, Brasil. Correspondência para/Correspondence to: C.L.B. AMBRÓSIO.E-mail:<cburgos@nutricao.ufpe.br>.

2 Curso de Pós-graduação em Nutrição, Universidade Federal de Pernambuco. Recife, PE, Brasil.
} 


\section{Methods}

The flakes were evaluated through analyses of coliforms at $45^{\circ} \mathrm{C}$, Escherichia coli, Staphylococcus aureus, Salmonela sp; counting of yeasts and molds; analysis of moisture, proteins, lipids, ash, dietary fibers, carbohydrates and carotenoids; storage stability; and acceptability of flakes added to beans and "pirão" (a widely consumed Brazilian dish consisting of meat and vegetable broth and cassava flour) by 188 adults and 67 children.

\section{Results}

The microbiological and physical-chemical characteristics of the flakes were adequate and the acceptability percentages were $95.21 \%$ for adults and $95.52 \%$ for children.

\section{Conclusion}

Dehydrated pumpkin flakes can be used in large scale to determine its effectiveness in the fight against hypovitaminosis $A$.

Indexing terms: sensorial analysis; carotenoids; dehydrated pumpkin flakes; hypovitaminosis $A$.

\section{N T R O D U Ç Ã O}

A abóbora, conhecida no nordeste do Brasil como jerimum, é bastante consumida nesta região e ocupa o quinto lugar em volume de comercialização no Estado de Pernambuco'.

Esta cucurbitácea constitui uma excelente fonte de carotenóides. Em 1990, Arima \& Rodríguez-Amaya², ao avaliarem a composição em carotenóides de abóboras provenientes do nordeste brasileiro, identificaram que a Cucurbita moschata, variedade baianinha, apresentava 19 carotenóides, dos quais o $\beta$-caroteno foi o principal pigmento encontrado, contribuindo com cerca de $74 \%$ do total médio de $317,8 \mu \mathrm{g} / \mathrm{g}$ desta espécie. De acordo com os autores, a abundância de $\beta$-caroteno na Cucurbita moschata, variedade baianinha, a torna uma das maiores fontes de provitamina A.

O valor médio de vitamina $A$ é quase 11 vezes o da Cucurbita maxima, variedade jerimum caboclo, e cinco vezes o da cultivar Cucurbita moschata, variedade menina verde ${ }^{3}$, abóbora até então considerada a mais rica entre as Cucurbitas e de maior comercialização em São Paulo.

Através da desidratação da abóbora obtêm-se os flocos. O processo de desidratação é econômico e simples e os equipamentos atualmente utilizados possibilitam uma elevada produção a custos reduzidos. Este processo permite ainda a redução do peso e do volume do produto inicial, o que facilita a embalagem, transporte e armazenamento do produto final. Quando adequadamente processados, embalados, transportados e armazenados, os flocos apresentam estabilidade microbiológica por um período mínimo de 180 dias$^{4}$.

A hipovitaminose $A$ constitui um grave problema de saúde pública e afeta milhares de crianças no mundo, especialmente em países em desenvolvimento, como o Brasil, podendo levar à cegueira e à morte. Os flocos desidratados de abóbora são uma fonte de provitamina $\mathrm{A}$ de baixo custo. A utilização deste produto como enriquecedor de produtos já existentes ou em formulações especiais, levando em consideração os atuais fatores de conversão de carotenóides em retinol ${ }^{5}$, poderia ser uma alternativa no combate à hipovitaminose $A$.

Este estudo se propôs a avaliar a aceitabilidade dos flocos desidratados de abóbora para que estudos posteriores possam avaliar a efetividade do produto em humanos no combate à hipovitaminose $A$, e desta forma, também estimular o cultivo da abóbora na região, trazendo benefícios tanto para os produtores rurais como para a agroindústria.

\section{MÉ TO D OS}

Para dar início à coleta de dados, o projeto obteve aprovação do Protocolo de Pesquisa 072/2002/CEP/CCS do Comitê de Ética em 
Pesquisa envolvendo seres humanos do Centro de Ciências da Saúde de Universidade Federal de Pernambuco.

Foram utilizadas na pesquisa abóboras do tipo moranga (Cucurbita maxima) e rasteira (Cucurbita moschata) comercializadas pelo Centro de Abastecimento Alimentar de Pernambuco (Ceasa/PE) e hipermercados da região metropolitana do Recife (PE). Após a aquisição, os frutos foram transportados para o Laboratório de Experimentação e Análise de Alimentos (LEAAL) Nonete Barbosa Guerra, do Departamento de Nutrição da Universidade Federal de Pernambuco (UFPE), para o processamento e análises laboratoriais.

Como embalagem primária foram utilizados sacos de polietileno com $26,8 \mathrm{~cm} \times 27,9 \mathrm{~cm}$ e como embalagem secundária caixas de papelão comum.

Os flocos desidratados de abóbora foram obtidos na planta piloto do Laboratório de Experimentação e Análise de Alimentos (LEAAL) Nonete Barbosa Guerra, por meio do processo de secagem baseado na metodologia descrita por Hoover ${ }^{6}$ e Fernandez et al. ${ }^{7}$ (Anexo).

Os flocos foram avaliados em duplicata quanto às características microbiológicas por meio das análises de coliformes a $45^{\circ} \mathrm{C}$, Escherichia coli, Staphylococcus aureus, Salmonela sp e contagem de bolores e leveduras segundo a American Public Health Association ${ }^{8}$.

As análises físico-químicas, também avaliadas em duplicata, foram de umidade, proteínas, lipídios, cinzas e fibra alimentar, de acordo com as normas da Association of Official Analytical Chemist (AOAC) ${ }^{9}$, carboidratos por diferença e carotenóides por meio da metodologia descrita por Rodríguez-Amaya ${ }^{10}$.

Antes do fechamento dos sacos de polietileno, os flocos foram submetidos a um jato de nitrogênio por aproximadamente um minuto. Posteriormente os flocos foram armazenados em ausência de luz a $28^{\circ} \mathrm{C}$ por 180 dias. Em intervalos pré-estabelecidos, amostras aleatoriamente coletadas foram avaliadas quanto à concentração de carotenóides e aspectos microbiológicos.
Os flocos foram adicionados ao feijão de 188 adultos (funcionários da UFPE, acompanhantes de pacientes e funcionários do Hospital das Clínicas de Pernambuco) com idade entre 20 e 60 anos, de ambos sexos, e ao pirão de 67 crianças com idade entre 3 e 6 anos de uma creche da Prefeitura da Cidade do Recife. A adição dos flocos ocorreu após a preparação do feijão e do pirão, não sendo, desta forma, submetidos a aquecimento posterior. A quantidade de flocos por pessoa foi calculada de acordo com a recomendação diária de vitamina A por faixa etária $(400 \mu g$ para crianças e $800 \mu \mathrm{g}$ para adultos) ${ }^{5}$.

Após o almoço, os adultos foram questionados acerca das características organolépticas do feijão por um grupo de estagiárias treinadas, do Laboratório de Bioquímica da Nutrição da UFPE, utilizando o teste afetivo qualitativo para entrevistas individuais (One-on-One Interviews), de acordo com a metodologia descrita por Ferreira et al. ${ }^{11}$.

No caso das crianças, foi utilizada uma escala hedônica facial (Figura 1) ${ }^{11}$. Durante o almoço, as professoras, auxiliadas pelas estagiárias, mostraram a escala para cada criança, de forma que as mesmas pudessem definir o que tinham achado da preparação. Com o intuito de confirmar a aceitabilidade do pirão oferecido, com e sem os flocos desidratados de abóbora, foi calculado o índice de rejeito do pirão oferecido para as crianças, pesando-o antes e após o almoço em quatro determinações.

Os testes de escala hedônica facial e entrevistas individuais (One-on-One Interviews) foram avaliados por meio das freqüências dos

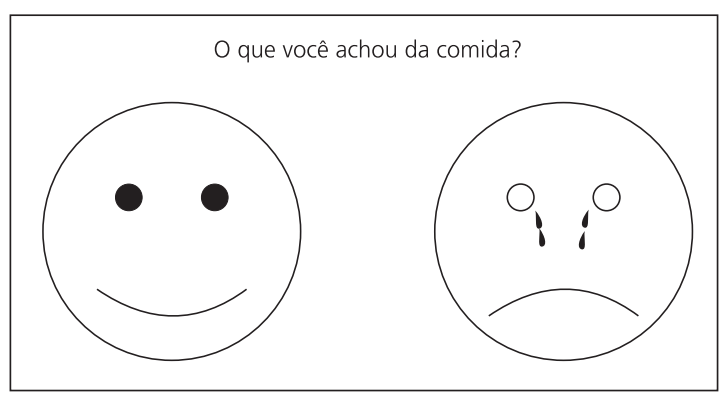

Figura 1. Escala hedônica facial apresentada às crianças. 
dados obtidos. Para análise da composição dos flocos e para comparação do índice de rejeito do pirão oferecido às crianças, com e sem flocos desidratados de abóbora, os dados foram submetidos ao teste " $\mathrm{t}$ " de Student ${ }^{12}$.

\section{RESULTADOS E DISCUSSÃ O}

O rendimento bruto (quilo de flocos obtidos por quilo de matéria prima processada) médio e o desvio padrão em nove ensaios foi de $8,89 \pm 1,26 \%$, com rendimento mínimo de 6,80\% e máximo de 10,82\%. Esta variação, esperada devido à falta de uniformidade da matéria prima, também foi constatada por Faro ${ }^{4}$, que obteve média de $8,30 \%$ e valores mínimo e máximo de $7,00 \%$ e $9,30 \%$, respectivamente.

A umidade da abóbora in natura é em torno $85 \mathrm{~g} / 100 \mathrm{~g}^{4}$. O teor de umidade final dos flocos desidratados de abóbora neste estudo foi de aproximadamente $7,31 \mathrm{~g} / 100 \mathrm{~g}$, valor similar ao de Faro $^{4}$, o que demonstra a eficiência do processo tecnológico de secagem utilizado (Tabela 1). Este teor de umidade pode ser considerado satisfatório por Rathod \& Udipi ${ }^{13}$, que concluíram que a maioria dos alimentos tem boa vida de prateleira quando apresenta teor de umidade inferior a 10g/100g.

Uma vez que se trata de produto desidratado, o teor de sólidos se encontra concentrado, de modo a tornar possível o fornecimento da ingestão diária recomendada (IDR) de seus componentes com pequena quantidade do produto. Os valores médios referentes aos percentuais de cinzas, proteínas, lipídios, carboidratos, fibra alimentar, carotenóides e valor energético total (VET) foram satisfatórios e similares aos obtidos por Faro 4 (Tabela 1).

De acordo com Menezes \& Lajolo ${ }^{14}$, a abóbora in natura apresenta em média 1,92g/100g de fibra alimentar, e Cecchi ${ }^{15}$ afirma que vegetais frescos podem conter de 0,4 a 2,1g/100g de cinzas, que foi comprovado por Faro ${ }^{4}$ que obteve valores médios de 1,9g/100 g de fibra alimentar e $0,78 \mathrm{~g} / 100 \mathrm{~g}$ de cinzas na abóbora in natura. Os elevados teores de cinzas e fibra alimentar dos flocos (Tabela 1) são de suma importância, uma
Tabela 1. Composição dos flocos desidratados de abóbora.

\begin{tabular}{|c|c|c|c|c|c|}
\hline \multirow{2}{*}{ Componentes } & \multicolumn{3}{|c|}{ Flocos analisados } & \multicolumn{2}{|c|}{ Faro $^{4}$} \\
\hline & M & \pm & DP & M & DP \\
\hline Umidade $\mathrm{g} / 100 \mathrm{~g}$ & 7,31 & \pm & $1,54^{\mathrm{a}}$ & 6,34 & $\pm 1,00^{a}$ \\
\hline Cinzas $\mathrm{g} / 100 \mathrm{~g}$ & 6,57 & \pm & $1,23^{\mathrm{a}}$ & 5,82 & $\pm 0,60^{a}$ \\
\hline Proteínas g/100g & 9,17 & \pm & $3,80^{\mathrm{a}}$ & 5,32 & $\pm 1,60^{a}$ \\
\hline Lipídios g/100g & 1,96 & \pm & $0,63^{a}$ & 1,59 & $\pm 0,40^{a}$ \\
\hline Carboidratos $\mathrm{g} / 100 \mathrm{~g}$ & 67,75 & \pm & $16,96^{\mathrm{a}}$ & 63,99 & $\pm 14,80^{*}$ \\
\hline Fibra alimentar $\mathrm{g} / 100 \mathrm{~g}$ & 19,49 & \pm & 3,29 & & $\pm 17,04^{*}$ \\
\hline Carotenóides mg/100g & 107,08 & \pm & $31,29^{a}$ & 106,27 & $\pm 25,47^{\mathrm{a}}$ \\
\hline V.C.T cal/100g & 325,33 & \pm & $50,51^{a}$ & 290,65 & $\pm 54,62^{a}$ \\
\hline
\end{tabular}

Os resultados analíticos correspondem à média de 4 determi-

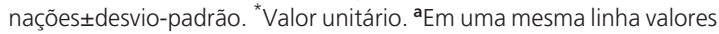
não diferem estatisticamente entre si a um nível de significância de $5 \%$, baseado no teste " $\mathrm{t}$ " de Student.

vez que já se tem conhecimento do papel benéfico dos micronutrientes e das fibras na saúde humana. Atualmente as fibras são um dos constituintes mais investigados como preventivos de doenças como câncer, problemas intestinais e diminuição do mau colesterol $(\mathrm{LDL})^{16}$.

Em quatro determinações realizadas, os valores referentes a coliformes a $45^{\circ} \mathrm{C}$ (Escherichia coli, Staphylococcus aureus), bolores e leveduras foram inferiores a 10UFC/g (Unidades formadoras de colônia/grama). Quanto à Salmonela sp, o resultado foi de ausência em $25 \mathrm{~g}$, o que comprova a qualidade da matéria prima e a utilização de boas práticas de processamento. Os resultados estão em conformidade com a legislação em vigor para produtos desidratados ${ }^{17}$.

O percentual de carotenóides caiu para $50,15 \%$ nos primeiros 30 dias e continuou decrescendo gradativamente até os 180 dias de armazenamento, demonstrando que não foi satisfatório o tratamento utilizado neste estudo (Figura 2).

Foi constatado por Faro 4 que o vácuo parcial possibilitou a redução das perdas deste constituinte de $49,31 \%$ para $10,21 \%$, entretanto o tratamento provocou uma compactação dos flocos, prejudicando uma das suas mais importantes características, a leveza.

É necessária a implementação de um estudo aprofundado que possibilite a utilização de tratamentos adequados no armazenamento 


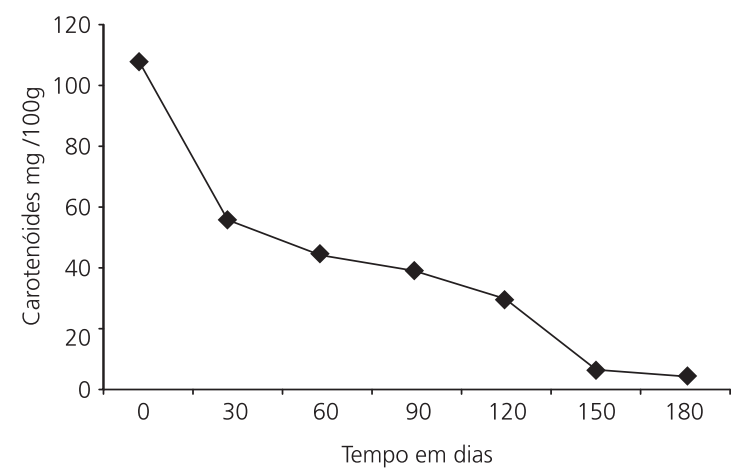

Figura 2. Quantidade de carotenóides ( $\mathrm{mg} / 100 \mathrm{~g}$ ) de flocos desidratados de abóbora ao longo do tempo de armazenamento.

dos flocos, favorecendo desta forma sua comercialização e utilização como fonte de carotenóides.

No que diz respeito ao aspecto microbiológico, o tratamento empregado foi eficaz. Após 180 dias de armazenamento os flocos desidratados de abóbora permaneceram com resultados em conformidade com a legislação em vigor para produtos desidratados ${ }^{17}$.

Em estudo anterior Faro ${ }^{4}$ avaliou as características organolépticas dos flocos desidratados de abóbora a partir de uma equipe de provadores devidamente treinada. A autora constatou uma satisfatória qualidade global dos flocos resultante das elevadas notas atribuídas à sua leveza, aparência geral, aroma, cor e, principalmente, da reduzida pontuação atribuída aos descritos: sabor estranho e adesividade na boca. As características organolépticas estabelecidas para os flocos desidratados neste estudo foram as seguintes: cor (alaranjada ligeiramente brilhante), sabor (próprio de abóbora: adocicado), aspecto (próprio e leve), aroma (próprio de abóbora: adocicado).

Neste estudo foi avaliada a aceitabilidade dos flocos em larga escala numa população constituída por adultos e outra por crianças.

Levando-se em consideração as atuais recomendações de vitamina A por faixa etária $(400 \mu \mathrm{g}$ para crianças e $800 \mu \mathrm{g}$ para adultos) e a conversão do $\beta$-caroteno em retinol (1:12) $)^{5}$ o valor médio de 107,08 mg/100g de carotenóides dos flocos (Tabela 1) e que em torno de $80 \%$ dos carotenóides da abóbora são do tipo $\beta$-caroteno, neste estudo foram adicionados $12 \mathrm{~g}$ ao feijão de cada adulto e $6 \mathrm{~g}$ ao pirão das crianças.

Dos 188 adultos que participaram da pesquisa, 6 não gostaram porque acharam que o feijão estava sem sal e apenas 1 não gostou porque identificou o sabor da abóbora e o achou intenso. O sabor doce dos flocos desidratados se sobressaiu ao sabor do sal adicionado ao feijão, o que resultou em um pequeno percentual de rejeição $(3,72 \%)$ por parte dos consumidores.

Dentre os provadores, 2 (1,06\%) acharam que o sabor do feijão estava razoável, mas não mencionaram o sabor da abóbora. Os demais 179 provadores $(95,21 \%)$ gostaram e alguns dos adjetivos utilizados foram de que o feijão estava grosso, cremoso, gostoso, ótimo e doce. Neste caso, o sabor adocicado aparece como fator positivo na aceitação.

Do total de crianças que participaram da pesquisa, 64 (95,52\%) aprovaram o sabor do pirão, identificando o desenho de satisfação na escala hedônica facial. Para comprovar o resultado obtido por meio deste teste, foi avaliado o índice de rejeição do pirão das crianças. O índice médio foi de $9,63 \%$ com desvio padrão de $0,64 \%$ para o pirão oferecido com os flocos e $11,66 \%$ com desvio de 1,32\% para aquele sem flocos. Não houve diferença estatisticamente significativa a um nível de $5 \%$ baseado no teste " $t$ " de Student, demonstrando que as crianças aceitaram bem os flocos de abóbora neste tipo de preparação, não fazendo distinção entre o pirão com ou sem o produto.

Os percentuais de aceitação de 95,21\% para os adultos e $95,52 \%$ para as crianças estão acima do ponto de corte sugerido por Teixeira ${ }^{18}$, em que um percentual acima de $70,00 \%$ de aprovação indica que o produto foi bem aceito. Estes dados demonstram que os flocos desidratados de abóbora podem ser utilizados em larga escala para o estudo do efeito deste produto no combate à hipovitaminose A. Em 2001, Faro ${ }^{4}$ constatou que ocorreu um aumento da reserva hepática de vitamina $\mathrm{A}$ em ratos, quando a dieta foi complementada com os flocos. Este dado constitui um estímulo na utilização dos flocos na dieta humana. 


\section{CONCLUS Ã O}

Os resultados obtidos, nas condições em que foi realizada a presente pesquisa, permitem concluir que os flocos desidratados de abóbora são excelentes fonte de carotenóides e poderiam ser utilizados no combate à hipovitaminose $A$. Para isto se faz necessário que estudos complementares sejam realizados, no intuito de testar a efetividade dos flocos em seres humanos, pois se trata de um produto barato, de fácil processamento e boa aceitabilidade, conforme demonstrado neste estudo.

Uma vez testada a efetividade dos flocos, este produto poderá ser utilizado em programas de combate à hipovitaminose $\mathrm{A}$, favorecendo não apenas comunidades carentes como estimulando o cultivo da abóbora na região, trazendo benefícios tanto para os produtores rurais como para a agroindústria.

\section{A GRADECIMENTOS}

Ao Laboratório de Experimentação e Análises de Alimentos (LEAAL) Nonete Barbosa Guerra, Laboratório de Bioquímica da Nutrição e Hospital das Clínicas da UFPE, Prefeitura da Cidade do Recife (Creche CEAPE - Centro de Aprendizagem de Pernambuco) e ao Conselho Nacional de Desenvolvimento Científico e Tecnológico.

\section{RE FER Ê N CIAS}

1. Silva RML. Estudo sobre a inocuidade das hortaliças de maior comercialização na CEAGEPE a partir da avaliação da utilização e emprego de pesticidas na produção [dissertação]. Recife: Universidade Federal de Pernambuco; 1996.

2. Arima HK, Rodríguez-Amaya DB. Carotenoid composition and vitamin $A$ value of a squash and a pumpkin from northeastern Brazil. Arch Latinoam Nutr. 1990; 40(2):284-92.

3. Arima HK, Rodríguez-Amaya DB. Carotenoid composition and vitamin A value of commercial brazilian squashes and pumpkins. J Micronutr Anal. 1988; 4:177-91.

4. Faro ZP. Aproveitamento industrial da polpa de abóbora [tese]. Recife: Universidade Federal de Pernambuco; 2001.
5. Dietary reference intakes for vitamin A, vitamin $K$, arsenic, boron, chromium, copper, iodine, iron, manganese, molybdenum, nickel, silicon, vanadium, and zinc. Washington (DC): National Academy of Sciences; 2001.

6. Hoover MW. A process for production of dehydrated pumpkin flakes. J Food Sci. 1973; 38(1):96-8.

7. Fernandez ZF, et al. Desenvolvimento de bebida láctea a base de flocos de abóbora. Arch Latinoam Nutr. 1998; 48(2):175-8.

8. Speck ML, editor. Compendium of methods for the microbiological examination of foods. Washington (DC): American Public Health Association; 1976.

9. Association of Official Analytical Chemists. Official Methods of Analysis of the AOAC. 16th ed. Washington (DC); 2002.

10. Rodríguez-Amaya DB. A guide to carotenoid analysis in foods. Washington (DC): ILSI Press; 1999. p.41-5.

11. Ferreira VLP, Almeida TCA, Pettinelli MLC, Silva MAAP, Chaves JBP, Barbosa EMM. Análise sensorial: testes discriminativos e afetivos. Campinas: SBCTA; 2000. p.126.

12. Vieira S. Introdução à bioestatística. 3 ed. Rio de Janeiro: Elsevier; 1980. p.196.

13. Rathod P, Udipi SA. The nutritional quality and acceptability of weaning food incorporating amaranth. Food Nutr Bull. 1991; 13(1):58-64.

14. Menezes EW, Lajolo FM, editores. Contenido en fibra dietética y almidón resistente en alimentos y productos iberoamericanos. Proyecto CYTED XI.6 Obtención y caracterización de fibra dietética para su aplicación en alimentos para regimenes especiales. São Paulo: Docuprint; 2000.

15. Cecchi HM. Fundamentos teóricos e práticos em análise de alimentos. Campinas: Unicamp; 1999.

16. Cândido LMB, Campos AMC. Alimentos funcionais: uma revisão. Bol SBCTA. 1995; 29(2):193-203.

17. Brasil. Agência Nacional de Vigilância Sanitária. Resolução RDC n.12 de 2 de janeiro de 2001. Aprova o regulamento técnico sobre padrões microbiológicos para alimentos. Diário Oficial da União, Brasília, Poder Executivo, de 10 de janeiro de 2001.

18. Teixeira E, Meinert EM, Barbetta PA. Análise sensorial de alimentos. Florianópolis: UFSC; 1987.

Recebido em: 16/4/2004

Versão final reapresentada em: 17/1/2005

Aprovado em: 30/5/2005 


\section{ANEXO}

\section{FLUXOGRAMA DO PROCESSO DOS FLOCOS DESIDRATADOS DE ABÓBORA}

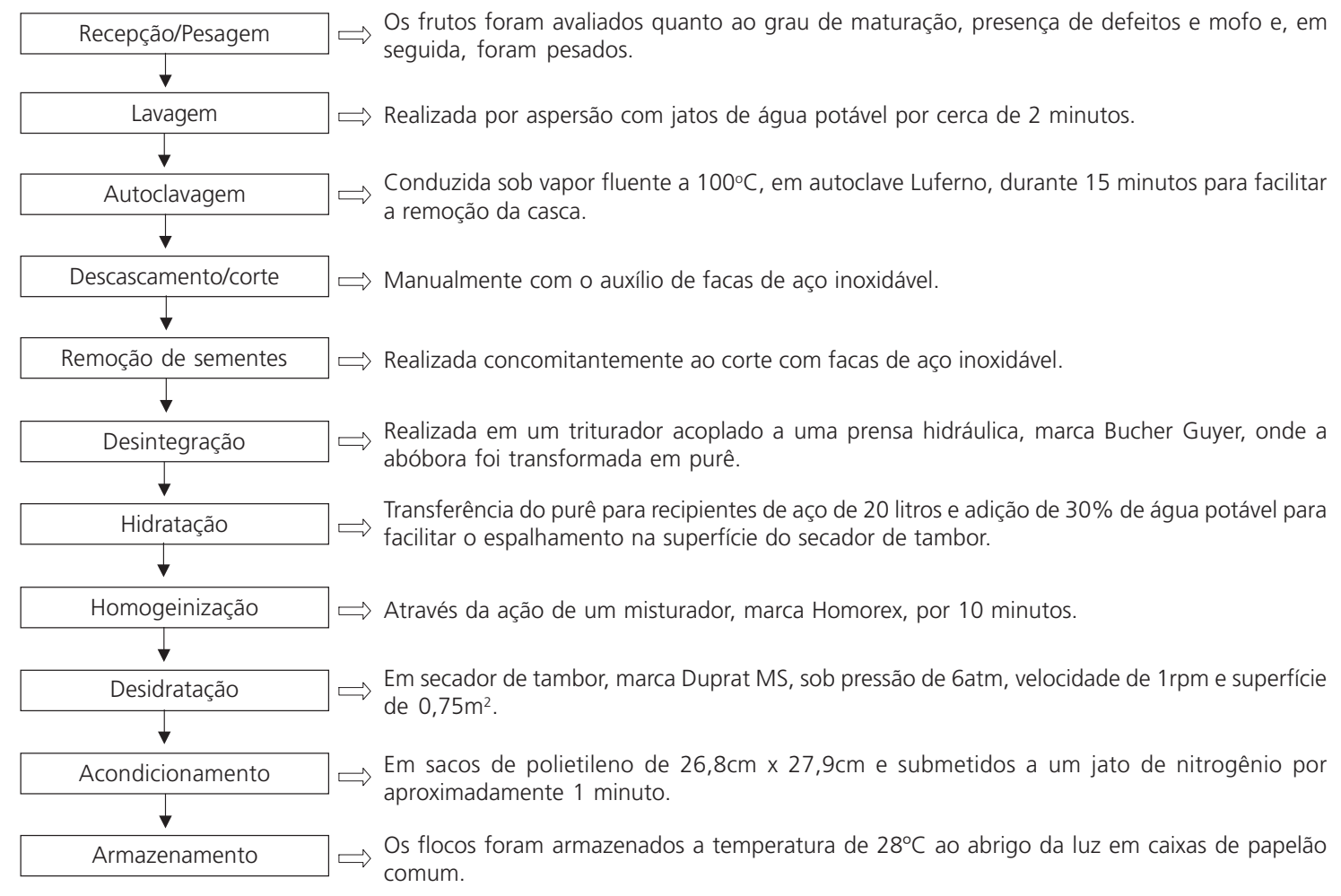

